Available online at http://jddtonline.info

RESEARCH ARTICLE

\title{
EFFECT OF GEMCITABINE ON FEMALE FERTILTY - AN ANIMAL MODEL STUDY
}

\author{
${ }^{1}$ Mohandas Rai, ${ }^{2}$ Sudha M J*, ${ }^{3}$ Viveka S, ${ }^{4}$ Kumaraswamy Kademane, ${ }^{5}$ Ashwini Mandanna, ${ }^{6}$ Rashmi R Rao, \\ ${ }^{7}$ Roopa P Nayak, ${ }^{1}$ Seethalakshmi
}

\author{
${ }^{1}$ Department of Pharmacology, A J Institute of Medical Sciences, Mangalore, India. PIN - 575004 \\ ${ }^{2}$ Department of Pharmacology, Azeezia Institute of Medical Sciences, Kollam, India. PIN - 691537 \\ ${ }^{3}$ Department of Anatomy, Azeezia Institute of Medical Sciences, Kollam, India. PIN - 691537 \\ ${ }^{4}$ Lecturer, International Medical University, Kuala Lumpur, Malaysia. \\ ${ }^{5}$ Medical Advisor, ZydusCadila, Ahemadabad, India PIN - 382210 \\ ${ }^{6}$ Department of Pharmacology, Kasturba Medical College, Mangalore, India. PIN - 575001 \\ 7Department of Pharmacology, DhanalakshmiSrinivasan Medical College, Perambalur, India \\ *Corresponding Author's Email: sudhasudhasudha@gmail.com, Mob: 09946654139
}

\begin{abstract}
Background and objectives:Advances in cancer chemotherapy have led to improved survival rates and poses greater emphasis on preserving quality of life post-treatment. Gonadotoxicity is a well-recognized side effect of many cancer chemotherapeutic agents. This study was designed to evaluate the effects of gemcitabine, an antimetabolite anticancer drug, on oogenesis in Swiss albino mice and its reversibility.

Methods:Thirty six inbred female Swiss albino mice in diestrous phase were selected and divided into three groups of twelve each. Groups were labelled as A, B and Control. Groups A and B received $40 \mathrm{mg} / \mathrm{kg}$ and $80 \mathrm{mg} / \mathrm{kg}$ of gemcitabine intraperitoneally. The control group received saline intraperitoneally. At the end of two weeks 6 mice were sacrificed from each group and the rest at the end of 2 months. Ovaries were studied histologically.

Results: After 2 weeks, the ovaries of experimental group mice showed more number of atretic follicles as compared to control group $(\mathrm{p}<0.01)$. The diameter of corpus lutea was more, though a reduction in number was recorded in experimental group $(\mathrm{p}<0.05)$. Whereas after 2 months, both the experimental groups showed no difference in terms of atretic follicles, diameter and number of corpus lutea $(\mathrm{p}>0.05)$.

Conclusions:These findings suggest that administration of gemcitabine may have profound effects on oogenesis and hence female fertility. This study also suggests that the effects are reversible.

Keywords:Gemcitabine; Oogenesis; Swiss albino mice; atretic follicles; corpus luteum.
\end{abstract}

\section{INTRODUCTION:}

Patients treated with cancer chemotherapy are at risk of infertility. Gametogenesis is highly regulated process and many physical, chemical and environmental factors can affect the final quality and quantity of gametes. Oogenesis in particular is more prone to such factors; being started early in intrauterine life, the process of ovum production will conclude only after fertilization. During this long journey the follicles will pass through primordial, primary and secondary stages before it becomes mature Graafian follicle and eventually to environmental factors may have higher chances of disrupting the process. During the formation of ovum, the dividing oocyte will halt at two specific steps, one at prophase of first meiosis and second arrest at metaphase of second meiosis. This peculiar aspect of oogenesis makes the process vulnerable for many disruptive environmental factors.

Gemcitabine, a fluorinated nucleoside antimetabolite drug, used for treatment of cancers of pancreas, breast, bladder and lung will also have adverse effects on fertility as they have detrimental action on gonads $^{1}$. Novel approaches in early detection and effective chemotherapeutic drugs have increased the survival rate of these patients, issue of fertility is of significance post treatment ${ }^{2,3}$.Mechanisms of ovarian toxicity differ with the anticancer drugs. It may involve loss of ovarian reserve. Alkylating agents accelerated the apoptosis of primordial follicles in both animal model and in preclinical studies ${ }^{4}$. Doxorubicin, an anthracycline antimetabolite can cross the blood-follicle barrier and induce apoptosis of oocyte ${ }^{5}$. Several studies have documented signs of fibrosis in the cortical stroma, and changes in the capillaries were observed in ovaries exposed to chemotherapy ${ }^{6,7}$. Oxidative stress may also play a role in gonadotoxicity from some of the chemotherapeutic agents like cyclophosphamide ${ }^{3}$.It has been shown that gemcitabine has adverse effects on spermatogenesis in mice model ${ }^{8}$.Fluoropyrimidines being the backbone of chemotherapy in many cancers, act on $\mathrm{S}$ - phase of cell cycle. Clinical data regarding its impact on fertility is limited. 5-Fluorouracil may result in premature ovarian failure ${ }^{9}$.A study performed on a mouse model shed light on a possible correlation between a potential toxic effect of 5-FU to ovarian function and a circadian timing of administration of the agent ${ }^{10}$. The evidence for a potential gonadotoxic effect of Imatinib mesylate is proven in mice ${ }^{11}$. A study on leukemic mouse model 
using therapeutic doses of Imatinib reports no effects on folliculogenesis or spermatogenesis ${ }^{12}$. Similarly many anticancer drugs including vinca alkaloids have shown no effects on follicles ${ }^{13}$.

Since many anticancer drugs have differential effects on ovarian functions, this study was designed to evaluate the effects of gemcitabine on oogenesis. Gemcitabine usually administered as single dose in treatment of cancers. The current study was designed to simulate the blood levels of therapeutic dose of gemcitabine in mice model.Few studies have done studies on effects of gemcitabine on ovaries ${ }^{8}$. Its reversibility hasn't been evaluated.

\section{MATERIALS AND METHODS}

The experiment was conducted on 50 day old Swiss albino mice, weighing $20-25$ grams. Mice were fed on standard feed and hosted in a 12 hour night day cycle environment and allowed water ad libitum. Optimum temperatures maintained throughout the experiment. The procedures and the handling of the mice were reviewed and approved by the Institutional Animal Care and Use committee. All mice received humane care in compliance with the CPCSEA.

Drug: Gemcitabine (Gemita lyophilized, Fresenius Kabi Oncology Ltd.) was dissolved in sterile water and intraperitoneally injected into mice using insulin syringes. The whole reconstituted drug was used for the study at once, within 24 hours, in order to maintain the potency of the reconstituted drug. Any unused reconstituted drug is discarded.

Study design: Around 60 inbred female Swiss albino mice were screened. Total thirty sixmice in diestrous phase were selected and divided into 3 groups of twelve each. Diestrous phase was determined by vaginal smear cytology. Groups were labelled control, A and B groups. Experimental groups i.e. A and B were given $40 \mathrm{mg} / \mathrm{kg}$ and $80 \mathrm{mg} / \mathrm{kg}$ of gemcitabine intraperitoneally respectively. Control mice were normal saline intraperitoneally once. After two weeks, that's at $14^{\text {th }}$ day after last intraperitoneal injection, half of the mice $(n=6)$ from each group were sacrificed by sodium pentobarbital injection and ovaries were dissected out and studied. Rest of the mice were sacrificed after 2 months and their ovaries were studied similarly. Gross features of ovaries and vascularity were noted at the time of dissection.

Histology: Mice ovaries are stored in Bouins' solution for 24 hours for fixation, processed and paraffin embedded. $5 \mu$ serial sections were taken and stained by standard hematoxylin and eosin.

Ovarian sections and classification of ovarian follicles: Follicle types in ovarian crosssectionswere defined as followed: Primordialfollicles comprised an oocytesurrounded by a single layer of cuboidalgranulosa cells. Primary follicles comprisedan oocyte surrounded by two ormore layers of granulosa cells with noantrum. Secondary follicles were distinguishedby an antrum within the granulosacell layers enclosing the oocyte. Atretic follicles were those displaying twoor more of the following criteria within asingle cross-section: more than twopyknotic nuclei, granulosa cells within theantral cavity, granulosa cells pulling awayfrom the basement membrane, and/oruneven layers of granulosa cells.Follicles without oocyte with degenerative or with no definitive granulosa cells and theca cells are considered as atretic follicles. Follicles without definitive oocyte with regularly arranged granulosa and theca (internal and external) cells are not considered for count of atretic follicles and their count was considered in subsequent serial sections. Estimation of number of follicles per ovary was made by incorporatingstereological sampling protocols ona predetermined fraction of ovarian serial sections. In present study, every $6^{\text {th }}, 10^{\text {th }}$ and $14^{\text {th }}$ sections were used. Follicles (withvisible nuclei) were counted if they appearedin one section but not the consecutive"look up" section, which ensured thatfollicles were counted only once.

The slides prepared were observed under the morphometric microscope and analysed using Jenoptik Optical Systems Digital morphometry microscope, Business Unit Digital Imaging, Goeschwitser Str. 25, 07745 Jena, Germany. Software used: ProgRes ${ }^{\circledR}$ Capture Pro 2.7 release 003. The size in terms of diameter, circumference and area of corpus lutea were measured.

Statistical analysis: All data observed were expressed as Mean \pm SD (standard deviation) and statistical significance of the histomorphometric data observed was performed by one-way ANOVA and Student ' $t$ ' test ( $p<0.05$ was accepted as statistically significant).

\section{RESULTS:}

\section{Gross morphology}

There was significant weight loss of ovary in A and B group both after 2 weeks in comparison to control group (table 1). The weights of ovaries in A and B groups were comparable and no statistical difference with control group after 2 months. There was decreased visible vascularity of the surface of ovaries after 2 weeks.

\section{The ovarian histomorphometry}

Control group mice showed normal architecture of primordial and primary follicles, Graafian follicles at various stages of development (Fig. 1). Ovaries of mice treated with gemcitabine showed significant decrease in number of primary and Graafian follicles $(\mathrm{p}<0.05)$ (Fig. 2). After 2 weeks of administration of gemcitabine, the ovaries showed significantly more atretic folliclesas compared to control group $(\mathrm{p}<0.01)$. There was no change in diameter, circumference and area of Graafian follicles in experimental mice in comparison to control group at end of 2 weeks $(\mathrm{p}=0.8)$. There was significant decrease in number, diameter, circumference and area of corpus luteum in ovaries of experimental mice with respect to control group $(\mathrm{p}<0.05)$.

After 2 months there was no significant difference between experimental group and control groups with respect to number of atretic and Graafian follicles. The difference in sizes of corpus lutea of experimental and control group had not differed significantly after 2 months of administration of drug (table 2). 
Table 1: Tabulation of weight of ovary, number of primordial, primary, secondary, Graafian, atretic follicles and corpus luteum with its size in mice treated withintraperitomeal gemcitabine for 7 days and sacrificed after 2 weeks. Each group $\mathrm{n}=6$. Data represented as Mean \pm standard deviation. $* \mathrm{p}<0.05$ between Group A and control and group B and control.

\begin{tabular}{|l|c|c|c|}
\hline At the end of $2^{\text {nd }}$ week & Group A & Group B & Control \\
\hline Ovary weight $(\mathrm{mg})$ & $2.84 \pm 0.38^{*}$ & $2.4 \pm 0.44^{*}$ & $3.58 \pm 0.8$ \\
\hline Number of follicles & $14.91 \pm 3.67^{*}$ & $12.56 \pm 1.25^{*}$ & $30.45 \pm 2.24$ \\
\hline Primordial & $8.72 \pm 3.23^{*}$ & $7.45 \pm 0.95^{*}$ & $12.54 \pm 3.42$ \\
\hline Primary & $2.11 \pm 1.13^{*}$ & $1.45 \pm 1.54^{*}$ & $6.42 \pm 2.12$ \\
\hline Secondary & $1.52 \pm 0.79^{*}$ & $1.85 \pm 0.92^{*}$ & $2.52 \pm 1.46$ \\
\hline Graafian & $2.33 \pm 1.36^{*}$ & $3.05 \pm 0.88^{*}$ & $1.54 \pm 0.55$ \\
\hline Atretic & $1.61 \pm 0.81^{*}$ & $1.75 \pm 0.56^{*}$ & $2.57 \pm 1.02$ \\
\hline Corpus luteum & $334.11 \pm 52.49^{*}$ & $298.12 \pm 45.40^{*}$ & $424.26 \pm 56.80$ \\
\hline Size & $1050.06 \pm 164.96^{*}$ & $1205.7 \pm 144.24^{*}$ & $1460.48 \pm 158.56$ \\
\hline Diameter $(\mu)$ & $359.73 \pm 108.19^{*}$ & $398.36 \pm 100.18^{*}$ & $454.25 \pm 121.26$ \\
\hline Circumference $(\mu)$
\end{tabular}

Table 2: Tabulation of weight of ovary, number of primordial, primary, secondary, Graafian, atretic follicles and corpus luteum with its size in mice treated with intraperitoneal gemcitabine for 7 days and sacrificed after 2 months. Each group $n=6$. Data represented as Mean \pm standard deviation.P $>0.05$ between group A and control, group B and control.

\begin{tabular}{|l|c|c|c|}
\hline & Group A & Group B & Control \\
\hline Ovary weight (mg) & $3.86 \pm 0.44$ & $3.58 \pm 0.26$ & $3.66 \pm 0.2$ \\
\hline Number of follicles & & & \\
\hline Primordial & $33.63 \pm 2.55$ & $30.42 \pm 0.56$ & $32.24 \pm 2.42$ \\
\hline primary & $12.89 \pm 3.12$ & $13.52 \pm 1.20$ & $12.62 \pm 3.24$ \\
\hline Secondary & $4.98 \pm 1.45$ & $5.2 \pm 0.95$ & $5.95 \pm 1.21$ \\
\hline Graafian & $2.73 \pm 0.85$ & $2.86 \pm 0.42$ & $2.65 \pm 0.54$ \\
\hline Atretic & $1.62 \pm 1.22$ & $1.85 \pm 0.75$ & $1.58 \pm 0.5$ \\
\hline corpus luteum & $2.05 \pm 0.65$ & $1.2 \pm 0.85$ & $2.95 \pm 0.65$ \\
\hline Size & & & \\
\hline diameter (micron) & $386.5 \pm 17.85$ & $405.65 \pm 42.56$ & $412.4 \pm 45.62$ \\
\hline circumference (micron) & $1180.48 \pm 108.32$ & $1286.92 \pm 112.48$ & $1265.45 \pm 142.22$ \\
\hline area (sq. micro) & $364.48 \pm 65.58$ & $400.58 \pm 88.9$ & $425.65 \pm 124.25$ \\
\hline
\end{tabular}

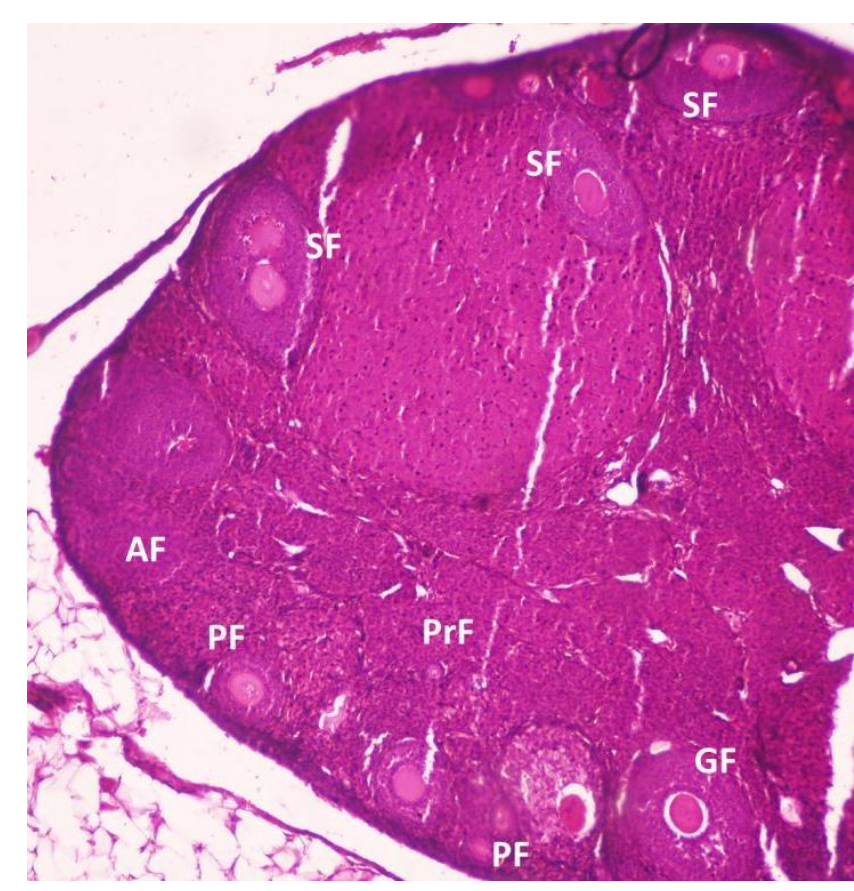

Figure 1: Normal architecture of control mice. $\mathrm{H} \& \mathrm{E}$ stain. 10X. PrF - Primordial follicle, PF - Primary follicle, SF Secondary follicle, AF - Atretic follicle, GF - Graafian follicle.



Figure 2: Histological changes in ovaries of group A mice after intraperitoneal gemcitabine injections. $\mathrm{H} \& \mathrm{E}$ stain. $10 \mathrm{X}$. PrF Primordial follicle, PF - Primary follicle, SF - Secondary follicle, $\mathrm{AF}$ - Atretic follicle, GF - Graafian follicle. ISSN: 2250-1177 


\section{DISCUSSION:}

Gemcitabine is an antimetabolite anticancer drug, used predominantly in chemotherapy of cancers of breast, pancreatic tumors and non-small cell lung carcinoma. Being a nucleoside analog it will interfere with DNA replication in actively dividing cells. Ovaries have got effective proactive and prosurvival mechanism for protection of germ cells. In this study it is attempted to explore the effects of disruptive agents like chemotherapeutic drugs on the ovarian architecture using gemcitabine.

It has been conclusively established in this study that gemcitabine disrupts the process of oogenesis. Gemcitabine administration has resulted in of increase in number of atretic follicles, decrease in number of primary follicles and decrease in size of corpus lutea. Similar results using Imatinib mesylate in rats' ovaries has been reported. Loss of oocyte in many of the follicles appreciated in present study may be due to initiation of oxidative stress and chromosomal obliteration. Similar oocyte toxic effects are reported in animal studies using doxorubicin $^{5}$ and platinum based compounds ${ }^{14}$.

Studies using other antimetabolite chemotherapeutic agents in animal models reinforce the present results. Toxic effects of 5-Fluorouracil have been shown in mice model and it has been proved that it brings phase dependent changes in ovarian functions ${ }^{15}$. Clinical data of the effects of antimetabolite agents on ovarian functions and intern fertility is very limited. Therefore the present study using mice model is of significance in

\section{REFERENCES:}

1. USP DI. Volume 1.Drug information for health care professional. Update monographs. Gemcitabine [Internet]. Micromedex Inc. 2013 [cited 2013 Oct 2]. p. 1-8. Available from: www.micromedex.com

2. Meirow D. Reproduction post-chemotherapy in young cancer patients. Molecular and Cellular Endocrinology. 2000 Nov 27;169(1-2):123-31.

3. Ben-Aharon I, Shalgi R. What lies behind chemotherapyinduced ovarian toxicity? Reproduction. 2012 Aug;144(2):153-63.

4. Meirow D, Lewis H, Nugent D \& Epstein M. Subclinical depletion of primordial follicular reserve in mice treated with cyclophosphamide: clinical importance and proposed accurate investigative tool. Human Reproduction, 1999, 14:1903-1907.

5. Bar-Joseph H, Ben-Aharon I, Rizel S, Stemmer SM, Tzabari M \&Shalgi R. Doxorubicin-induced apoptosis in germinal vesicle oocytes. Reproductive Toxicology, 2000; 30:566-572.

6. Meirow D, Dor J, Kaufman B, Shrim A, Rabinovici J, Schiff E, Raanani H, Levron J \&Fridman E. Cortical fibrosis and bloodvessels damage in human ovaries exposed to chemotherapy chemotherapy. Potential mechanisms of ovarian injury. Human Reproduction, 2007;22(6):1626-33.

7. Oktem O \&Oktay K. Quantitative assessment of the impact of chemotherapy on ovarian follicle reserve and stromal function. Cancer, 2007, 110:2222-2229.

8. Baker SOA. Gemcitabine impacts histological structure of mice testis and embryonic organs. Pakistan Jornal of Biological Scicences. 2009;12(8):607-15. proving the detrimental effects of gemcitabine on oogenesis.

In the present study it was noted that the size of corpus luteum were reduced after 2 weeks of administration of drug. This is in contrast to a similar study using Imatinib on mice where an increase in corpus luteum size is reported $^{12}$. Differential timing in administration of drug with respect to estrous cycle may explain differential effects brought by these gonadotoxic agents. Present study conclusively proves that the ovarian toxic effects will fade off and most of detrimental effects are reversible after 2 months of administration of insulting agent. Such reversibility in animal model is not reported in literature so far to the best of our knowledge. This was evident by near normal appreciation of ovarian architecture histologically with no significant difference in number of primordial, primary, Graafian and atretic follicles in ovaries of experimental animals and in control group. The size of corpus lutea in experimental and control group did not differ significantly. We conclude that the effects of gemcitabine are reversible after 2 months at least with respect to histological architecture in animal model.

Limitations: Present study is designed to evaluate histological effects only. This study has not shown light on ovarian functions which can be analysed through estimation of hormones in blood.

Merits: This study evaluates the reversibility of effects of gemcitabine after its acute effects fades off. The results will have crucial implications when the drug is administered to young females.

9.Azem F, Amit A, Merimsky O \& Lessing JB. Successful transfer of frozen-thawed embryos obtained after subtotal colectomy for colorectal cancer and before fluorouracil-based chemotherapy. Gynecologic Oncology, 2004; 93:263-265.

10. Hrushesky WJ, Vyzula R \& Wood PA. Fertility maintenance and 5-fluorouracil timing within the mammalian fertility cycle. Reproductive Toxicology, 1999;13: 413-420.

11. ParichehrehYaghmaei, KazemParivar FJ. Effect of Imatinib on oogenesis and pituitary- ovary hormal axis in female wistar rat.International Joutnal of Fertility and Sterility. 2009; 3(1):11-6.

12. Schultheis B, Nijmeijer BA, Yin H, Gosden RG \&Melo JV 2012 Imatinib mesylate at therapeutic doses has no impact on folliculogenesis or spermatogenesis in a leukaemic mouse model. Leukemia Research, 2012; 36: 271-274.

13. Zekri JM, El-Helw LM, Purohit OP, Hatton MQ \& Coleman RE.Epirubicin/vinorelbine adjuvant chemotherapy in young women with breast cancer is associated with preservation of menstrual function. Clinical Oncology, 2008; 20: 513-516.

14. Gonfloni S, Di Tella L, Caldarola S, Cannata SM, Klinger FG, Di Bartolomeo C, Mattei M, Candi E, De Felici M MG al. Inhibition of the c-Abl-TAp63 pathway protects mouse oocytes from chemotherapy-induced death. Nature Medicine. 2009; 15:1179-85.

15. Hrushesky WJ VR\& WP.Fertility maintenance and 5fluorouracil timing within the mammalian fertility cycle.Reproductive Toxicology. 1999;13:413-20. 